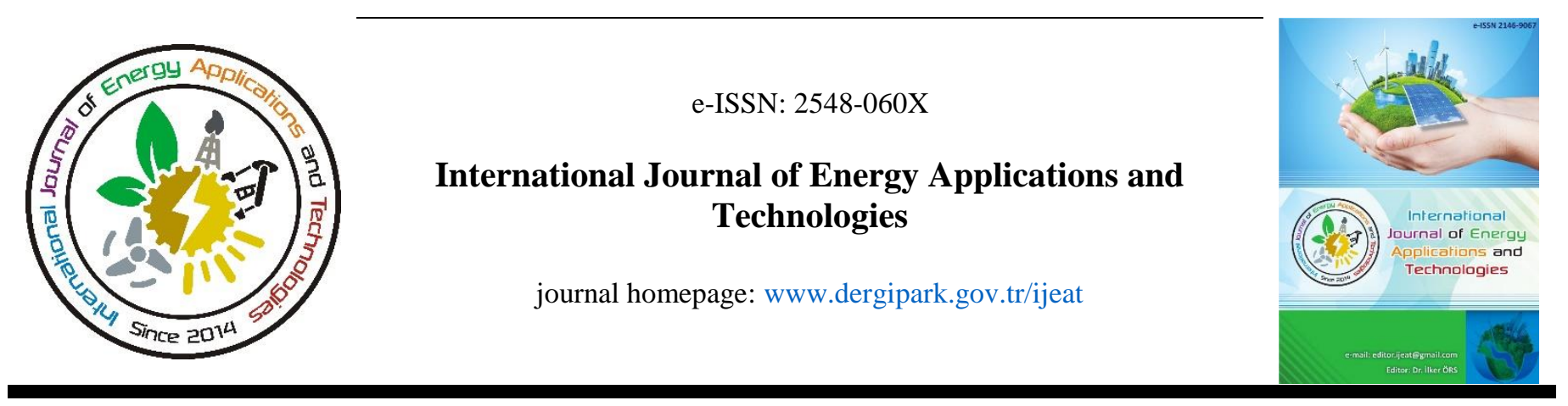

Review Article

\title{
Effects of biodiesel usage on mechatronic components in automobiles with diesel engine: A review
}

hosted by Turkish JourkinalPark

\author{
Sinan Erdoğan \\ Ministry of Industry and Technology, KOSGEB, Marmara Directorate, Istanbul. Turkey
}

\author{
ARTICLE INFO \\ * Corresponding author \\ erdogan.sinan@gmail.com \\ Received May 19, 2019 \\ Accepted June 11, 2019 \\ Published by Editorial Board \\ Members of IJEAT \\ (C) This article is distributed by \\ Turk Journal Park System under \\ the CC 4.0 terms and conditions. \\ doi: 10.31593/ijeat.567555
}

\begin{abstract}
The extinction of petroleum-based fuel resources and reducing regulations of the environmental pollution compel engine manufacturers and researchers to develop alternative fuels and highperformance engines. New generation diesel engines developed in recent years; equipped with high-pressure injection systems, modern dispenser pumps, and improved injectors. The use of alternative fuels in this new generation of mechatronic systems is also an issue examined by researchers. During engine operation, biodiesel, one of the renewable alternative fuels, can cause reduced engine performance, heavy carbon and varnish deposits in mechatronic components, and actual damage to the engine. In this study, mechatronic systems constituting engine management system are introduced. The effects of biodiesel usage on new generation diesel engines with the common rail injection system are investigated and the problems encountered in the use of biodiesel are evaluated.
\end{abstract}

Keywords: Diesel engine, Mechatronic components, Common rail, Diesel oxidation catalyst, Selective catalytic reduction

\section{Introduction}

The older generation diesel engines were running noisily by producing environmentally polluting emissions. Due to their negative features, they were not preferred to use apart from commercial vehicles. The advancement of technology has seriously affected the development of diesel engine equipment. In addition, these technological developments have been triggered by measures to reduce environmental pollution in the world.

The development of technology with very interdisciplinary approaches in a very complex and rapid manner caused electro-mechanical systems to take place in automobiles. Thus, the concept of automotive mechatronics has emerged. Thanks to new generation products, automobiles are equipped with mechatronic systems. High performance, economical, safe, comfortable and environmentally friendly cars are produced with the contribution of mechatronic systems. Mechatronics systems used in automobiles are grouped as engine management systems, security-related systems, driving-related systems, comfort-related systems, and other systems. Engine management systems are consists of fuel injection systems, ignition systems, idling control systems, and emission control systems [1]. Unlike spark ignition engines (gasoline engines), compression ignition engines (diesel engines) do not need an ignition system [2]. The older generation diesel engines are equipped with a fuel injection pump which is driven directly by the engine and only the engine speed is controlled. The new generation diesel engines are equipped with high-pressure spray systems, modern dispenser pumps, and improved injectors. After the development of high-pressure injection systems as an engine equipment, common rail (CR) injection system for passenger cars was first introduced in 1997 by Bosch [3]. The 
new generation diesel engines are equipped with highpressure spray systems, modern dispenser pumps, and improved injectors. These engines are equipped with a pump which is driven directly by the engine and injectors which is sprayed the calculated amount of fuel into the cylinder at the calculated time by pressurizing the fuel independently of the engine speed. The new generation diesel engines are much cleaner, more economical, and powerful with turbocharging systems, exhaust gas recirculation (EGR), catalytic converter, and programmed information processing units for environmental sensitivity. Nowadays, these diesel engines have started to find a place in passenger cars because of their low fuel consumption, cleaner and more comfortable. In a promotion sheet, it is stated that on a 2.0-liter diesel engine with the common rail system of $1800 \mathrm{bar}$, the engine torque is increased by $35 \%$, the engine power is increased by $24 \%$, and the low idle noise is reduced by $6.5 \mathrm{~dB}$, as compared with the conventional model of the company [4].

Along with developments in engine technology, renewable fuels are also developing. At the beginning of the years when biodiesel as an alternative fuel entered our lives, edible oils have used as raw materials. These oils derived from canola, soybean, rapeseed, olive, palm, corn, mustard, rice, wheat, coconut, etc. are evaluated as first generation feedstocks of biodiesel. Since these oils have used as food, it is not preferred to use them in biodiesel production. This situation led to the development of the second generation biodiesel. This biodiesel is produced from the non-edible vegetable oils of crops so as not to affect food production and price. Cottonseed, jatropha, mahua, karanja, neem, linseed, and camelina are non-edible vegetable oils. As well as, animal fats used as second-generation feedstocks are beef tallow, pork lard, yellow grease, chicken fat, and fish oil. After that, waste oil (cooking oil, frying oil), recycled oil (pyrolytic oil of plastic or tire), and algae have used as the third generation of feedstocks [5]. Biodiesel mixtures can be used without major equipment modification in compression ignition engines. However, biodiesel has many advantages such as high cetane number, non-toxic, and low sulfur levels. But, the disadvantages are lower heating values, higher viscosity, and lower volatility [6]. Biodiesel can be preferred to reduce engine emissions. In fact, it can reduce carbon dioxide $\left(\mathrm{CO}_{2}\right)$ emissions by $80 \%$, carbon monoxide (CO) emissions by $40 \%$, and minimize hydrocarbon (HC) emissions and sulfur particles [7].

Although the physical and chemical properties of biodiesel fuels are very similar to diesel fuel, their different aspects affect the operation and life of the engine. The mass flow rate changes in the injectors cause pollutant emission changes such as nitrogen oxides $\left(\mathrm{NO}_{\mathrm{x}}\right)$. The operational conditions of a CR injection system compose a pressure wave in the injector's feed pipe. This pressure wave can change the mass flow rate distributed by the injector. Eventually, fuel characteristics affecting these pressure waves will affect the total mass injected so, the injection process [8]. In the use of biodiesel, carbon deposits can form on and around the injector tip, a thin layer of deposition can observe at the metal holder of the fuel filter. These may lead to clogging of the injection pumps, injectors, and filters. As a result, problems such as a reduction in engine performance, increase in engine noise, start ability failure of the engine occur and these problems cause mechatronic components to deteriorate in a short time. In this study, mechatronic components which constitute the management system of diesel engines are introduced and the effects of biodiesel use on these components have been investigated.

\section{Engine Management System and Its Components}

The engine management system (EMS) adjusts the ignition timing and control the amount of fuel being injected. The EMS helps to provide maximum engine power with the lowest amount of exhaust emissions and fuel consumption. The sub-elements of the EMS are the fuel injection system, the emission control system and the engine control unit (ECU).

\subsection{New generation fuel injection system}

Almost all of the newly produced passenger cars are used as a fuel injection system as CR injection system. The first CR system was introduced by Bosch. The system has a common high-pressure reservoir (common rail) that supplies fuel to all cylinders. In conventional diesel injection systems, the fuel pressure must be produced separately for each injection. However, in the CR system, pressure production and injection are separate operations. Thus, fuel required for the fuel injection is always present at the desired pressure [9] The schematic diagram of the system is given in Figure 1.

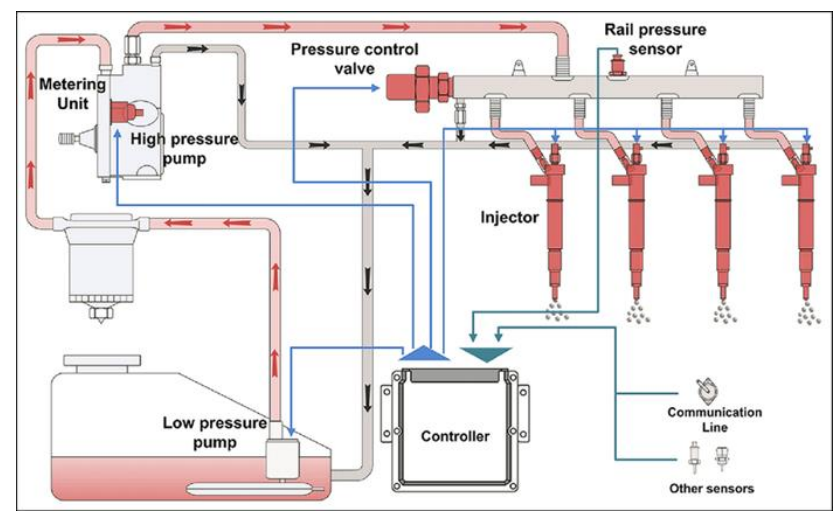

Figure 1. The schematic diagram of the CR injection system [10]

The pump compresses the fuel and sends it into the line with a high pressure pipe, which acts as a common high pressure chamber for all injectors, so it is called the common rail. The fuel is dispensed into the independent injectors, which inject the fuel into the combustion chamber of the cylinder. The 
injectors of the CR injection system provide clean and highly efficient combustion with extremely short durations and multiple injections. Thus, the system provides high engine power and low fuel consumption. As well as, the system causes low emissions. Due to the modular design of the system, it can be used in all vehicle models.

In a report, new common-rail engine (plus some other improvements) can save $20 \%$ of fuel consumption, double the torque at low revs and increase capacity to $25 \%$. In addition, this engine significantly reduces the noise and vibration of conventional diesel engines. In terms of emissions, greenhouse gases $\left(\mathrm{CO}_{2}\right)$ decreased by $20 \%$, $\mathrm{CO}$ $40 \%$, unburnt $\mathrm{HC}$ and particles by $60 \%$ [2].

The components of a CR injection system include a common spray line (a common rail), a high pressure pump and fuel injectors.

\subsubsection{High pressure pump}

The low pressure pump sends the fuel in the fuel tank to the high pressure pump. The high-pressure pump compresses the fuel and continuously sends it to the high-pressure chamber. So the system pressure is kept constant continuously. High pressure pump designs have been improved to achieve higher efficiency of the fuel injection system and to ease accurate rail pressure control. Because the pressure generation is not dependent on engine speed, the desired pressure can be used even at low engine speeds. Radial, unit and in-line pumps are used in commercial CR systems. Most of the CR systems have radial piston pumps. High pressure pumps work at pressures up to approximately 1,600 bar for the engine of the passenger cars, in future up to 1,800 bar [9].

\subsubsection{Fuel injectors}

The injector in a CR system is composed of the nozzle and connections for actuation of the nozzle needle. According to the injector type, it also contains a solenoid valve for solenoid valve injectors or an actuator for piezo injectors. The injectors are assembled separately in each engine cylinder and integrated to the rail. The injectors are supplied with fuel from the rail through the high pressure pipe. The number and location of the holes in the channel vary with the systems. The common rail injectors do not open with hydraulic fuel pressure as conventional diesel injectors. The common rail injectors are electrically actuated by the ECU. Every injector is controlled separately by the ECU that provides that the nozzle needle is opened or closed by the piezo actuator or solenoid valve. Injectors with piezo actuators operate at a particularly low noise level. Fuel injection systems depend not only on complicated software in the ECU, but also the injectors have become more and more complexed with ultrafast acting piezo-electric injector actuators. They can allow up to five independent injections per combustion cycle for optimized engine efficiency [11]. Both injectors fulfill pre-injection, main injection and secondary injection for clean and efficient combustion. Common-rail injection systems operate at an injection pressure of maximum 1,800 bar for the engine of the passenger cars [9].

\subsubsection{Common rail}

All injectors are connected to the common rail with the highpressure pipe. The duty of the pressure regulator (pressure control valve) connected to the rail ensures that the highpressure circulation on the rail, depending on the operating state of the motor remains constant at the desired values.

\subsection{Engine control unit (ECU)}

In the engine management system, all information required for the control of the drive component is processed. To achieve this, the sensors collect all data related to the current operation of the motor. According to this data, the engine control unit regulates the operation of the injectors according to the driving situation. The sensors convert the various physical values, such as fuel temperature, engine speed or load, into electrical signals to determine the current operating status. The most important sensors for the Common-Rail injection system are; engine speed sensor, fuel temperature sensor, fuel pressure sensor on the rail, suction pipe pressure sensor, camshaft first cylinder position sensor and etc. [9].

\subsection{Emission control systems}

Non-toxic exhaust gases throw from the exhaust to the environment as a result of combustion are $\mathrm{N}_{2}, \mathrm{O}_{2}, \mathrm{H}_{2} \mathrm{O}, \mathrm{CO}_{2}$. Toxic gases that are harmful to human health and the environment, released by the exhaust are $\mathrm{CO}, \mathrm{NO}_{\mathrm{x}}, \mathrm{SO}_{2}, \mathrm{HC}$, particulate matter (PM). As shown in Figure 2, the distributions of exhaust gases are approximately $67 \% \mathrm{~N}_{2}$, $12 \% \mathrm{CO}_{2}, 11 \%, \mathrm{H}_{2} \mathrm{O}, 9 \% \mathrm{O}_{2}$ and the amount of toxic gas is $1 \%$. Most of the absorbed nitrogen is ejected with residual gases, only a small part of it reacts with oxygen $\mathrm{O}_{2}$ and forms $\mathrm{NO}_{\mathrm{x}}$. Pollutant emissions have a rate of less than $1 \%$ in the exhaust gas. $\mathrm{NO}_{\mathrm{x}}$ has the highest percentage of pollutant emissions with a rate of more than $50 \%$. The second highest ratio is the $\mathrm{PM}$ in pollutant emissions. The concentration of $\mathrm{CO}$ and $\mathrm{HC}$ is minimum due to the diesel running principle [12].

All newly registered diesel passenger cars have to supply to a $\mathrm{NO}_{\mathrm{x}}$ emission limit of the Euro 6 standard. All diesel passenger car manufacturers have succeeded in fulfilling this requirement in laboratory tests. However, it is accepted that the "real world" $\mathrm{NO}_{\mathrm{x}}$ emissions of diesel passenger cars are actually above the standards [13]. Emission control systems preferred by the diesel passenger car manufacturers are examined in two groups. These are (1) technologies used inside of the engine, and (2) aftertreatment technologies. In order to minimize emissions inside of the engine, there is a mechatronic system called exhaust gas recirculation (EGR) system. Aftertreatment emission control systems are (1) diesel oxidation catalyst (DOC), (2) selective catalytic 
reduction (SRC), and (3) diesel particulate filter (DPF).

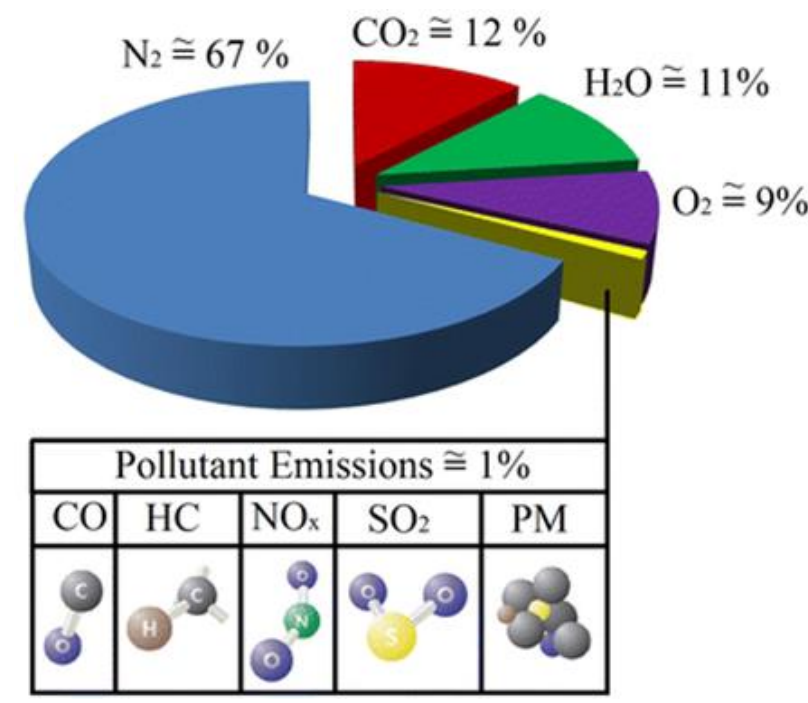

Figure 2. The compositions of exhaust gas [12]

\subsubsection{Exhaust gas recirculation (EGR)}

Nitrogen inside of the air and oxygen react at very high combustion temperature. Availability of oxygen in the cylinder and high temperature are the main cause of $\mathrm{NO}_{\mathrm{x}}$ formation. The EGR system is the technique of reducing $\mathrm{NO}_{\mathrm{x}}$ emissions used in diesel engines. The EGR system operates by rotating some of the engine's exhaust gas back into the engine cylinders. The schematic diagram of the EGR is given in Figure 3.

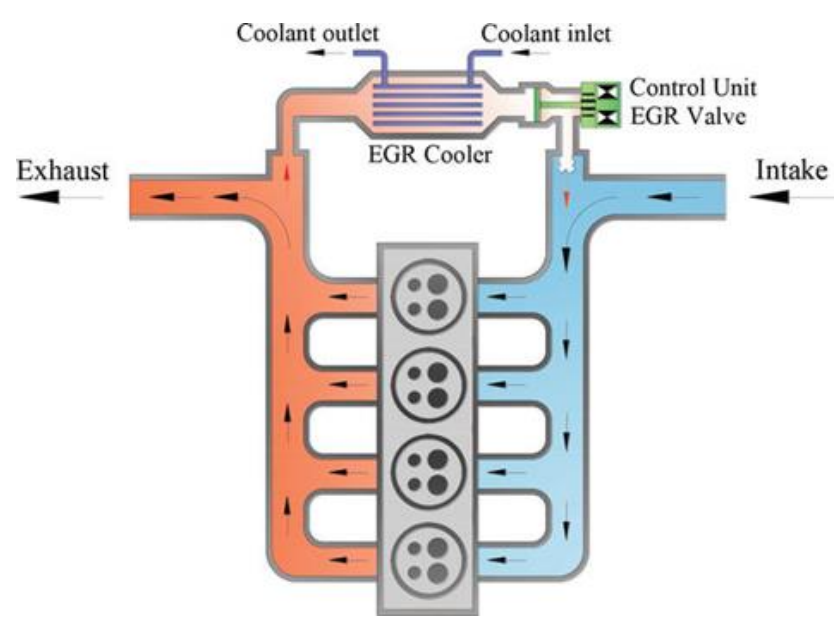

Figure 3. The EGR system [14]

The use of the EGR system causes to fall the amount of oxygen in the cylinder. This situation will be resulting in a reduction in the combustion end temperature and pressure. The reduction of oxygen restrains the generation of $\mathrm{NO}_{\mathrm{x}}$. The circulation of the exhaust gas with the inlet air can be provided in external and internal ways. In the external EGR, the exhaust gas taken from the exhaust manifold is sent to the inlet stream through a valve and a coolant. In the internal EGR, a certain rate of the exhaust gas return to the combustion chamber before exiting the exhaust valve. The internal EGR is generally used in spark ignition engines while external EGR systems are widely preferred in compression ignition engines. The exhaust gas is passed through a cooler and sent to the inlet stream. The cooling of the exhaust gas allows a higher amount of exhaust gas to be included in a new combustion cycle. Therewith, $\mathrm{NO}_{\mathrm{x}}$ emissions can be further decreased. Although the EGR system reduces the $\mathrm{NO}_{\mathrm{x}}$ emission in diesel engines by up to $50 \%$, the combustion becomes worsen, fuel consumption increases by up to $2 \%$, and the PM emission increases slightly [14]. The EGR is not performed while the engine is running at full load because there is a large amount of oxygen in the combustion chamber for good power gain. The EGR system is controlled by the ECU.

\subsubsection{Diesel oxidation catalyst (DOC)}

The task of the catalyst is to convert the polluting gases to harmless gases. The catalysts used in the catalytic converter are called oxidation catalysts. They convert $\mathrm{CO}$ and unburned HC. The catalyst consists of a stainless steel outer casing. Inside the casing, there is a ceramic block in the honeycomb structure. The honeycomb structure increases the contact surfaces of the active metals with exhaust gases. Active metals cause chemical reactions in the catalytic converter. These reactions convert harmful gases into harmless gases. Since it contacts the active metal, the carbon of $\mathrm{CO}$ and $\mathrm{HC}$ uses oxygen remaining in the exhaust gas [12]. The catalysts have constituted of an inert material coated with platinum, iridium, rhodium, palladium, or some alloy. These can eliminate $\mathrm{HC}, \mathrm{CO}$, and $\mathrm{NO}_{\mathrm{x}}$ emissions, and partly diminish particulates. The converter oxidizes $\mathrm{CO}$ and $\mathrm{HC}$ to $\mathrm{CO}_{2}$ and $\mathrm{H}_{2} \mathrm{O}$ and at the same time degrades $\mathrm{NO}_{\mathrm{x}}$ to nitrogen [15]. The schematic diagram of the DOC in Figure 4.

\subsubsection{Selective catalytic reduction $(\mathrm{SCR})$}

It is very easy to separate $\mathrm{HC}$ and $\mathrm{CO}$ emissions from the exhaust gas by using an oxidation catalyst. However, the removal of $\mathrm{NO}_{\mathrm{x}}$ when oxygen is existing in the exhaust gas is very complex. The nitrogen $\left(\mathrm{N}_{2}\right)$ may be separated in a $\mathrm{NO}_{\mathrm{x}}$ storage catalyst or using an SCR converter. The $\mathrm{NO}_{\mathrm{x}}$ storage catalyst is coated with chemical compounds that have an inclination to bond strongly with $\mathrm{NO}_{2}$. The reducing agent in the SCR converter is oxidized selectively with oxygen in $\mathrm{NO}_{\mathrm{x}}$ instead of the oxygen molecule in the exhaust gas. In this case, ammonia $\left(\mathrm{NH}_{3}\right)$ can be used as a selective reducing agent. $\mathrm{NH}_{3}$ can be produced from non-toxic carrier substances, such as urea or ammonium carbamate. AdBlue is a brand name, but its content is $32.5 \%$ aqueous urea solution which is toxic and non-flammable. The urea in AdBlue reacts with the exhaust gas at high temperature to convert to $\mathrm{NH}_{3}$, which reacts with $\mathrm{NO}_{\mathrm{x}}\left(\mathrm{NO}\right.$ and $\left.\mathrm{NO}_{2}\right)$ in the SRC converter to harmless $\mathrm{N}_{2}$ and $\mathrm{H}_{2} \mathrm{O}$ [9]. $\mathrm{NH}_{3}$ reacts $\mathrm{NO}$ and $\mathrm{NO}_{2}$ compounds in the exhaust gas into non-hazardous gases such as $\mathrm{H}_{2} \mathrm{O}$ and $\mathrm{N}_{2}$ as seen in Figure 4. 


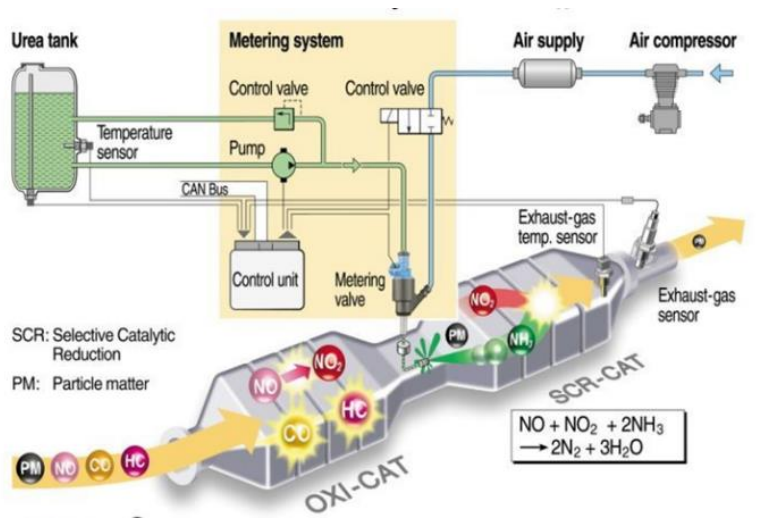

Figure 4. The schematic diagram of the SCR and DOC [16]

\subsubsection{Diesel particulate filter (DPF)}

The structure of the DPF is designed to allow the particles to be held on the surfaces and on the bottom sides of the clogged channels (Figure 5). This step is called the loading phase. The particle filter consists of a ceramic block impregnated with precious metals. The ceramic block is similar to the block of a conventional catalyst. However, one of the two channels in the particle filter is blocked. The material between the channels is permeable and allows exhaust gases to pass through. Commercial examples are available in which DPF is added to the exhaust line before or after the DOC.

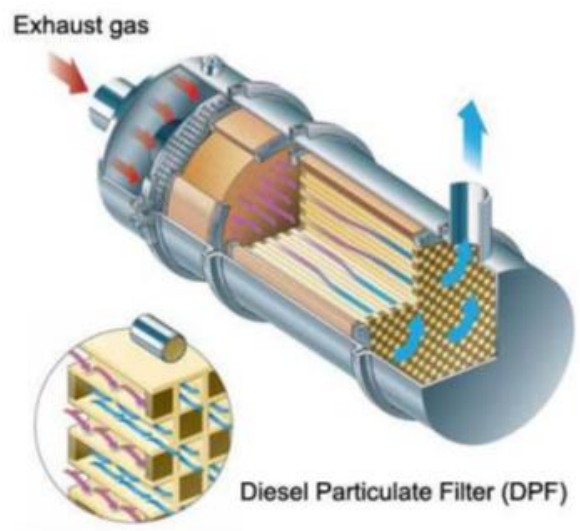

Figure 5. The schematic diagram of the DFP [17]

\section{Effects of Biodiesel Usage}

The injection timing, injection speed and injection pressure of the engine with a CR injection systems are affected by the use of biodiesel. In addition, the cyclic fuel distributing, pressure wave spread time, mean injection rate, and maximum pressure during injection are importantly impressed. Fuel injection pressure has a considerable influence on $\mathrm{NO}_{\mathrm{x}}$ and smoke. Commonly, an increase in injection pressure results in a reduction in smoke emissions and an increase in $\mathrm{NO}_{\mathrm{x}}$ emissions. In $\mathrm{CR}$ injection systems, the pressure wave propagation is rather minor due to the constant rail pressure. Therefore, biodiesel effects are extremely eliminated in the CR system. In spite of that, during the operation of the system, pressure waves are formed in the injector's feed pipe, which can change the mass flow rate in the injector. Consequently, these pressure waves can impress the aggregate fuel mass injected, especially in a multi-injection situation [15].

By Tziourtzioumis and Stamatelos [18], the impact of fuel characteristics on a change of the injection pressure has examined on a turbocharged engine, equipped with four cylinders and electronically controlled injection system using biodiesel. According to the results, the rail pressure has risen when biodiesel is supplemented to diesel (D100) as given Figure 6. Biodiesel has a lower heat value than diesel, so more fuel requires to be injected into the cylinder to enable the same power. Hence a higher fuel consumption is materialized. Therefore, rail pressure for the biodiesel-diesel fuel blend (B70) has increased. Although pressure fluctuation is weakened in a single injection situation, in a multi-injection situation, higher density fuel exhibits a little pressure wave amplitude.

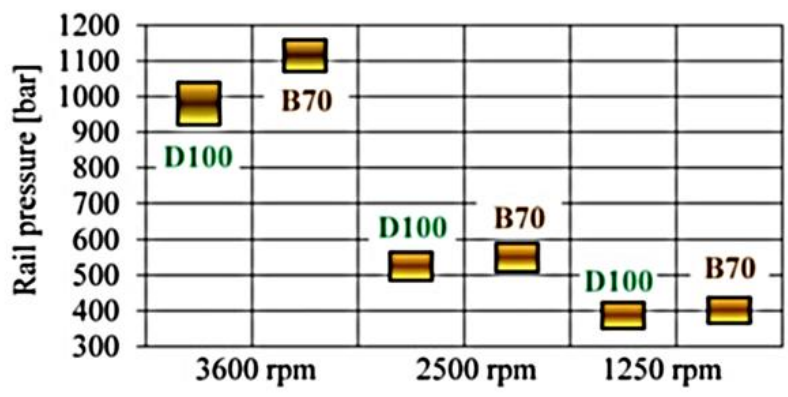

Figure 6. Rail pressures at different engine speeds of diesel and B70 fuels [18]

The injection timing or start of injection is a very significant parameter for all engine characteristics. The injection timing affects the quality of the air-fuel mixture, the combustion process, and consequently, harmful emissions. The delayed injection causes lower cylinder temperatures and reduces $\mathrm{NO}_{\mathrm{x}}$ emissions. Nevertheless, it leads to an increase in fuel consumption. In CR injection system, the effect of fuel characteristics on injection timing is rather minor. Spray development depends considerably on turbulence and cavitation in the injector orifice. Mostly, smaller orifice diameters cause better atomization and surface evaporation of the spray, combined with higher injection pressures. Moreover, the cavitation situation, fuel exit speed, and the discharge coefficient are significantly affected by the shape and dimension of the nozzle hole. In reality, the longer spray tip penetration and narrower cone angles occur in biodiesel usage. The geometry of the injector's nozzle holes is one of the most considerable parameters in the injection system. A diminution of the rounding radius of the inlet edge of a cylindrical nozzle hole typically rises the turbulence and cavitation inside the orifice by causing to a wider spray angle [15]. 
Bouilly et al. [19] examined the effects of biodiesel oxidation stability on the diesel fuel injection component in the fuel test rig with a $\mathrm{CR}$ injection system consisting of two solenoid injectors. An increase in the injector body temperature accelerates the corruption of fuel. Consequently, fuel injection component has given earlier a failure. A rough engine idling, power loss, combustion noise increase or start ability failure have been noticed since starting to use biodiesel. They have often caused by injector internal deposits, lead to injection deterioration. Biodiesel is known to have poor oxidation stability and to generate sediments from the polymerization of the fuel aged. In conclusion, they form deposits inside the injector. Two types of deposits might be found inside the fuel injection component when biodiesel used. These are brownish lacquered appearance deposits and white or yellow waxy appearance deposits.

Chaikool et al. [6] have investigated the effect of using biodiesel on the common-rail injection nozzle in a diesel engine. Diesel fuel and two palm oil biodiesel blends (B5 and B10) have supplied to the nozzles, at the 1,800 bar injection pump pressure and constant 2,200 rpm engine speed during 1,000 hours. In the study, it is stated that there is no wearing around the injection nozzle holes when B5 and B10 used. Moreover, according to the results by the scanning electron microscope (SEM), the contaminations have observed around the holes. The diameter of the nozzle hole tested with diesel, B5 and B10 are approximately $130 \mu \mathrm{m}, 120 \mu \mathrm{m}$, and $115 \mu \mathrm{m}$, respectively to the SEM images. The nozzles tested using B5 and B10 are coated by some particles. In this case, the hole diameters have decreased. There has been no wear in the use of biodiesel but there has been contamination around the perforations. It has been analyzed elements of the particle adherent around the nozzle holes via the energy dispersive $\mathrm{x}$-ray (EDX) analyzer. It has seen that excessive carbon $(\mathrm{C})$ and oxygen $(\mathrm{O})$ accumulate in the nozzle holes. This sediment has caused the disappearance of the iron $(\mathrm{Fe})$ peaks.

In a study, the behavior of the internal nozzle flow has been examined using diesel and soybean oil biodiesel at cavitating and non-cavitating conditions, using a homogeneous equilibrium model taking into account the turbulence effects. In modern diesel engines, cavitation can occur in fuel injection nozzles when injection pressure reaches up 1800 bar. When biodiesel is used, more fuel is injected from the injectors for the same engine performance and thus, the upper cavitation limit is reached. But cavitation density is lower for the same pressure situations. Since the reduction of injection speed and cavitation density for the biodiesel, the air-fuel mixing operation deteriorates. It is stated that biodiesel inhibits cavitation compared to standard diesel fuel [7]. In another study, after the use of biodiesel, SEM and EDX analyses were carried out and the surfaces of injection system components such as the injector nozzle and injector pump were examined. In the tests, one of the engines has been supplied with $100 \%$ biodiesel (B100) and it has used diesel in the other engine. Both engines have been the same features and have been operated at the same conditions throughout $200 \mathrm{~h}$. According to the analysis results, B100 fuel has given rise to chemical reactions on the surfaces of the components. There has been a considerable rise in the amounts of $\mathrm{Si}$ and $\mathrm{C}$ in the injector nozzle. Physicochemical reactions between metal surfaces and biodiesel generated a passive layer on some metal surfaces that may reduce the level of wear. Nevertheless, oxidation and corrosion phenomenon due to the chemical structure of biodiesel increases the level of wear. The high temperature of combustion raises the acidity of biodiesel and raises the propensity of chemical reaction of biodiesel. In the study, chemical reactions between the metal surfaces and biodiesel have been expressed. Biodiesel has reacted with $\mathrm{Si}$ and $\mathrm{C}$ in the combustion chamber and injector nozzle. The high temperature in there has been increased the density of $\mathrm{Si}$ and $\mathrm{C}$ on the surfaces of the injector nozzle. Without the high combustion temperature, biodiesel reacted with $\mathrm{Mn}, \mathrm{Cr}, \mathrm{V}$, and $\mathrm{C}$ on the surfaces of the components, this is creating a passive sheet on the metal surface and hindering wear. It has been monitored that not to be higher wear in the pump piston using biodiesel. The results of the study about the injection system components are given in Table 1 and Table 2 [20].

Table 1. EDX results of the engine injector exposed to different fuels [20]

\begin{tabular}{lcccc}
\hline & \multicolumn{2}{c}{ Diesel } & \multicolumn{2}{c}{ Biodiesel } \\
\hline Element & $\begin{array}{c}\text { Beginning } \\
(\text { wt } \%)\end{array}$ & $\begin{array}{c}\text { End of } \\
\text { the tests } \\
(\text { wt } \%)\end{array}$ & $\begin{array}{c}\text { Beginning } \\
(\text { wt } \%)\end{array}$ & $\begin{array}{c}\text { End of } \\
\text { the tests } \\
(\text { wt } \%)\end{array}$ \\
\hline $\mathbf{C}$ & 17.664 & 24.136 & 17.524 & 43.521 \\
$\mathbf{S i}$ & 0.593 & 0.26 & 0.828 & 22.708 \\
$\mathbf{V}$ & 0.077 & 0.094 & 0.177 & 0.166 \\
$\mathbf{C r}$ & 1.503 & 1.506 & 1.171 & 0.288 \\
$\mathbf{M n}$ & 0.709 & 0.333 & 0.979 & 0.156 \\
$\mathbf{F e}$ & 77.205 & 72.041 & 76.993 & 5.932 \\
$\mathbf{N i}$ & 2.249 & 1.63 & 2.727 & 0.193 \\
\hline
\end{tabular}

Table 2. EDX results of the engine injector pump piston exposed to different fuels [20]

\begin{tabular}{lcccc}
\hline & \multicolumn{2}{c}{ Diesel } & \multicolumn{2}{c}{ Biodiesel } \\
\hline Element & $\begin{array}{c}\text { Beginning } \\
(\text { wt } \%)\end{array}$ & $\begin{array}{c}\text { End of } \\
\text { the tests } \\
(\text { wt \%) }\end{array}$ & $\begin{array}{c}\text { Beginning } \\
(\text { wt } \%)\end{array}$ & $\begin{array}{c}\text { End of } \\
\text { the tests } \\
\text { (wt \%) }\end{array}$ \\
\hline $\mathbf{C}$ & 2.067 & 5.227 & 2.141 & 12.982 \\
$\mathbf{S i}$ & 1.51 & 0.364 & 0.538 & 0.468 \\
$\mathbf{V}$ & 1.224 & 0.448 & 0.317 & 0.57 \\
$\mathbf{C r}$ & 2.037 & 0.702 & 1.026 & 1.237 \\
$\mathbf{M n}$ & 1.616 & 0.919 & 0.418 & 0.539 \\
$\mathbf{F e}$ & 90.738 & 91.661 & 92.856 & 82.567 \\
$\mathbf{N i}$ & 2.875 & 0.678 & 2.703 & 1.637 \\
\hline
\end{tabular}

In another study by Liaquat et al. [21], the effects of diesel fuel (DF) and PB20 (20\% palm biodiesel and 80\% DF) on injector nozzle deposits have investigated. The results of the research showed that some deposit accumulation on injectors 
during running on both fuels. According to EDX and SEM analyses, greater carbon deposits on and around the injector tip for PB20 compared to diesel as seen in Figure 7.

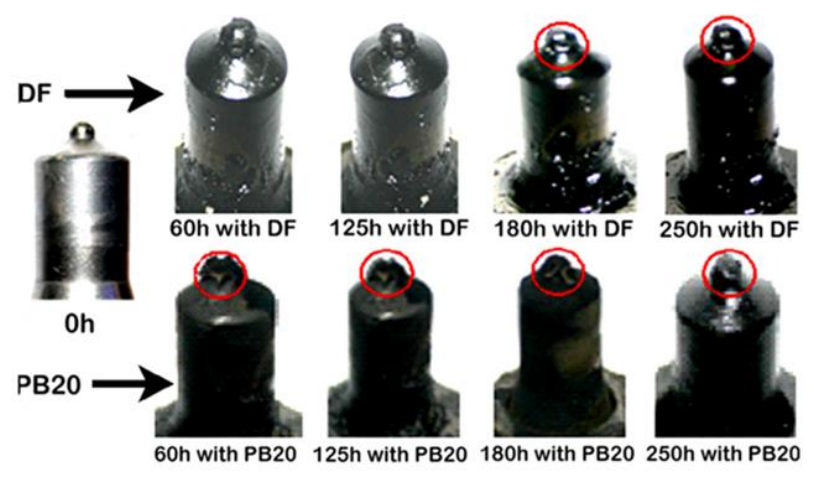

Figure 7. Pictures of injector nozzles on the test [21]

In the other study by Liaquat et al. [22], the effect of diesel and JB20 (20\% jatropha biodiesel and $80 \%$ diesel) blend on injector deposit and lubricating oil were investigated during the $250 \mathrm{~h}$ endurance test. The metallic particles existing in the engine oil observed throughout the test. When JB20 is used in the engine, the amount of these particles is higher than when diesel is used.

In research by Kapilan [23], the fuel injection components such as fuel lining tube, fuel filter, and gasket have been retained for a period of time in beakers containing diesel, jatropha biodiesel (B100), and B5 fuels. Corrosion and sediment deposition processes were monitored in these components. A thin layer of sediment was observed in the metal holder of the fuel filter held in the beaker with B100, due to the higher unsaturated components of it. When these components are held in the beaker with B5 and diesel, it has been expressed that no sediment was accumulated. As a result, it has stated that $\mathrm{B} 5$ fuel can be used easily without making any changes in engine components.

\section{Conclusion}

In the most investigations, it is reported that engine power and torque, unburned $\mathrm{HC}, \mathrm{CO}$, and $\mathrm{PM}$ in general decrease when biodiesel used in diesel engines. A positive feature is also that biodiesel reduces wear on the engine parts. On the other hand, $\mathrm{NO}_{\mathrm{x}}$ typically increases and if the power is kept constant, the fuel consumption increase. Additionally, biodiesel usage can cause the formation of sediments, the deterioration of materials, or the obstruction of filters because of biodiesel's degradability, cold flow properties, glycerol content, and other properties.

Despite all the possible problems concerned with biodiesel usage, biodiesel help to reduce harmful emissions. The highpressure fuel pump, common rail pipeline, pressurized systems that provide continuous information in accordance with the combustion process, new generation injectors, further optimized turbocharger and EGR system, guarantees more efficient and effective combustion. Increased $\mathrm{NO}_{\mathrm{x}}$ emissions by using biodiesel are minimized by the SCR system. With the increasing production of new generation vehicles, the SRC system will start to appear in many vehicles. For this reason, vehicle manufacturers develop special indicators for AdBlue filling. In the future, the car will not be able to run if the AdBlue tank is empty. For this reason, a warning will be displayed in the instrument panel and attention will be drawn to the limited range. The tank will be filled with the filling pipe on the right side of the diesel tank cap.

It is recommended that a smaller amount of biodiesel, such as B20, be mixed with diesel since reducing the thermo oxidation of fatty acid. Adding antioxidants to biodiesel can be useful to moderate the reaction mechanisms. Currently, the disadvantages of diesel fuel systems have been overcome by improving components such as high-pressure pumps, injectors, hoses for high-pressure fuel, and automatic control applications on high pumps. In the future, mechatronic components will develop further, and there will be serious changes especially in ECU. The biodiesel mixing ratio will be determined by the ECU and the operating conditions of the engine will be optimized according to the biodiesel ratio. New sensors and actuators will be added to the engines. In this context, the fuel injection angle, injection time, injection pressure, and injection quantity will be adjusted by the ECU. The EGR ratio and AdBlue spray rate will be optimized according to the biodiesel ratio detected.

\section{References}

[1] Gümüş M, Akkuş N, Binark AK. Automotive Mechatronics Education. OTEKON'04 Automotive Technologies Congress. Bursa, Turkey 21-23 June 2004. p. 351-8.

[2] Pham VV, Cao DT. A Brief Review of Technology Solutions on Fuel Injection System of Diesel Engine to Increase the Power and Reduce Environmental Pollution. Journal of Mechanical Engineering Research \& Developments (JMERD). 2019;42(1):1-9.

[3] Jost K. New common-rail diesels power Alfa's 156. Automotive Engineering. 1998;106(1):36-8.

[4] DENSO. Diesel Common Rail Sell Sheet - DSL-CRSS1007. http://densoheavyduty.com/diesel-fuel-injection; 2019.

[5] Sakthivel R, Ramesh K, Purnachandran R, Shameer PM. A review on the properties, performance and emission aspects of the third generation biodiesels. Renew Sust Energ Rev. 2018; 82:2970-92.

[6] Chaikool P, Intravised K, Patsin P, Laonapakul T. A study of effect of biodiesel on common-rail injection nozzle. SAE International Journal of Fuels and Lubricants. 2016;9(3):712-6. 
[7] Salvador F, Martínez-López J, Romero J-V, Roselló MD. Influence of biofuels on the internal flow in diesel injector nozzles. Mathematical and Computer Modelling. 2011;54(7-8):1699-705.

[8] Boudy F, Seers P. Impact of physical properties of biodiesel on the injection process in a common-rail direct injection system. Energ Convers Manage. 2009;50(12):2905-12.

[9] Reif K. Diesel engine management: Springer, 2014.

[10] Hong S, Shin J, Sohn J, Park I, Sunwoo M. Coordinated control strategy for the common-rail pressure using a metering unit and a pressure control valve in diesel engines. Proceedings of the Institution of Mechanical Engineers, Part D: Journal of Automobile Engineering. 2015;229(7):898-911.

[11] Schöner H-P. Automotive mechatronics. Control engineering practice. 2004;12(11):1343-51.

[12] Reşitoğlu İA, Altinişik K, Keskin A. The pollutant emissions from diesel-engine vehicles and exhaust aftertreatment systems. Clean Technologies and Environmental Policy. 2015;17(1):15-27.

[13] Yang L, Franco V, Campestrini A. NOX control technologies for Euro 6 Diesel passenger cars. Market penetration and experimental performance assessment. The International Council on Clean Transportation; 2015.

[14] Reşitoğlu İA. NOx Pollutants from Diesel Vehicles and Trends in the Control Technologies. Diesel Engines: IntechOpen; 2018.

[15] Kegl B, Kegl M, Pehan S. Green diesel engines. Biodiesel Usage in Diesel EnginesSpringer-Verlag, London. 2013.

[16] Dziubiński M. Testing of exhaust emissions of vehicles combustion engines. Environmental engineering V. 2017:305-9.

[17] Lázaro MJ, Galvez ME, Ascaso S, Suelves I, Moliner R, Pieta I, et al. Catalytic technologies for diesel engines exhaust gas cleaning. In: Song M, editor. Catalysis: Principles, Types and Applications: Nova Science Publishers; 2011.

[18] Tziourtzioumis D, Stamatelos A. Effects of a $70 \%$ biodiesel blend on the fuel injection system operation during steady-state and transient performance of a common rail diesel engine. Energ Convers Manage. 2012;60:56-67.

[19] Bouilly J, Mohammadi A, Iida Y, Hashimoto H, Geivanidis S, Samaras Z. Biodiesel stability and its effects on diesel fuel injection equipment. SAE Technical Paper; 2012.

[20] Celik I, Aydin O. Effects of B100 biodiesel on injector and pump piston. Tribology Transactions. 2011;54(3):424-31.
[21] Liaquat A, Masjuki H, Kalam M, Fazal M, Khan AF, Fayaz H, et al. Impact of palm biodiesel blend on injector deposit formation. Applied energy. 2013; 111:882-93.

[22] Liaquat A, Masjuki HH, Kalam M, Varman M. Impact of biodiesel on injector deposit formation. The 5th AUN/SEED-Net Regional Conference on New/Renewable Energy Hanoi, Viet Nam, 26-27 September 2012.

[23] Kapilan N. Effect of Biodiesel on Few Components of Fuel Injection System. Acta Technica CorvininesisBulletin of Engineering. 2014;7(3). 